\title{
Parameter Analysis on Wind-Induced Vibration of UHV Cross-Rope Suspension Tower-Line
}

\author{
Xilai Li, ${ }^{1}$ Dengke $Y u,{ }^{1}$ and Zhengliang $\mathrm{Li}^{2}$ \\ ${ }^{1}$ The Electric Power Planning \& Engineering Institute Co., Ltd., Xicheng District, Beijing 100120, China \\ ${ }^{2}$ The Civil Engineering Department, University of Chongqing, Shapingba District, Chongqing 400045, China \\ Correspondence should be addressed to Dengke Yu; dkyu@eppei.com
}

Received 6 December 2016; Accepted 24 January 2017; Published 16 February 2017

Academic Editor: John Mander

Copyright (c) 2017 Xilai Li et al. This is an open access article distributed under the Creative Commons Attribution License, which permits unrestricted use, distribution, and reproduction in any medium, provided the original work is properly cited.

\begin{abstract}
This paper analyzes the influences of important structural design parameters on the wind-induced response of cross-rope suspension tower-line. A finite element model of cross-rope suspension tower-line system is established, and the dynamic timehistory analysis with harmonic wave superposition method is conducted. The two important structural design parameters such as initial guy pretension and sag-span ratio of suspension-rope are studied, as well as their influences on the three wind-induced vibration responses such as tensile force on guys, the reaction force on mast supports, and the along-wind displacement of the mast top; the results show that the value of sag-span ratio of suspension-rope should not be less than $1 / 9$ and the value of guy pretension should be less than $30 \%$ of its design bearing capacity. On this occasion, the tension in guys and compression in masts would be maintained in smaller values, which can lead to a much more reasonable structure.
\end{abstract}

\section{Introduction}

The cross-rope suspension tower-line is similar in structure to the hybrid structure in suspended cable system to provide elastic support for the split conductors suspended through insulators by using the cross-rope between the ends of double-mast, and for setting up double-mast itself and maintaining the load balance of entire tower, it is necessary to lay out guys at the two sides of the double-mast, which, as a tension structure system, is of a complex nonlinear problem, of which key structural design parameters include the initial guy pretension and the sag-span ratio of suspension-rope, which will have a significant impact on the wind-induced vibration response of the structure.

Issa and Avent proposed discrete-field analysis method and compiled related program for the analysis of guyed towers [1]. Ben Kahla proposed an approximate analysis method of the guyed tower by simplifying guyed tower mast to equivalent curved beam [2]. Sparling has put forward that the initial tensile force of guy-wires not only can provide the towers with wind direction stiffness, but also will affect across-wind stiffness, and both are mutually coupled [3].
Madugula et al. established the finite element program, simulating lattice mast with beam element, used to study the influence of the initial pretension of guys on structure dynamic response [4]. Wahba et al. discussed the finite element modeling method of two different guyed tower. One is three-dimensional truss element modeling and the other is curved beam element. And it is shown by lots of numerical calculation that the latter is more accurate [5]. Kewaisy proposed hybrid mixed finite element model of guyed towers for consideration of nonlinear effects [6]. Desai and Punde used the generalized finite element method to study the dynamic characteristics of suspension structure [7]. Horr et al. made nonlinear dynamic analysis by use of nonlinear frequency domain analysis method [8]. Meshmesha et al. presented an equivalent curved beam finite element method to analyze the response characteristics of guyed towers under static and dynamic loads and made the comparison with classical finite element analysis method to verify the accuracy of the new method [9]. Shi and De Oliveira et al. also made the relevant analysis of guyed towers using the finite element method [10, 11]. Gani and Légeron analyzed two types of guyed tower structures and pointed out that equivalent static 


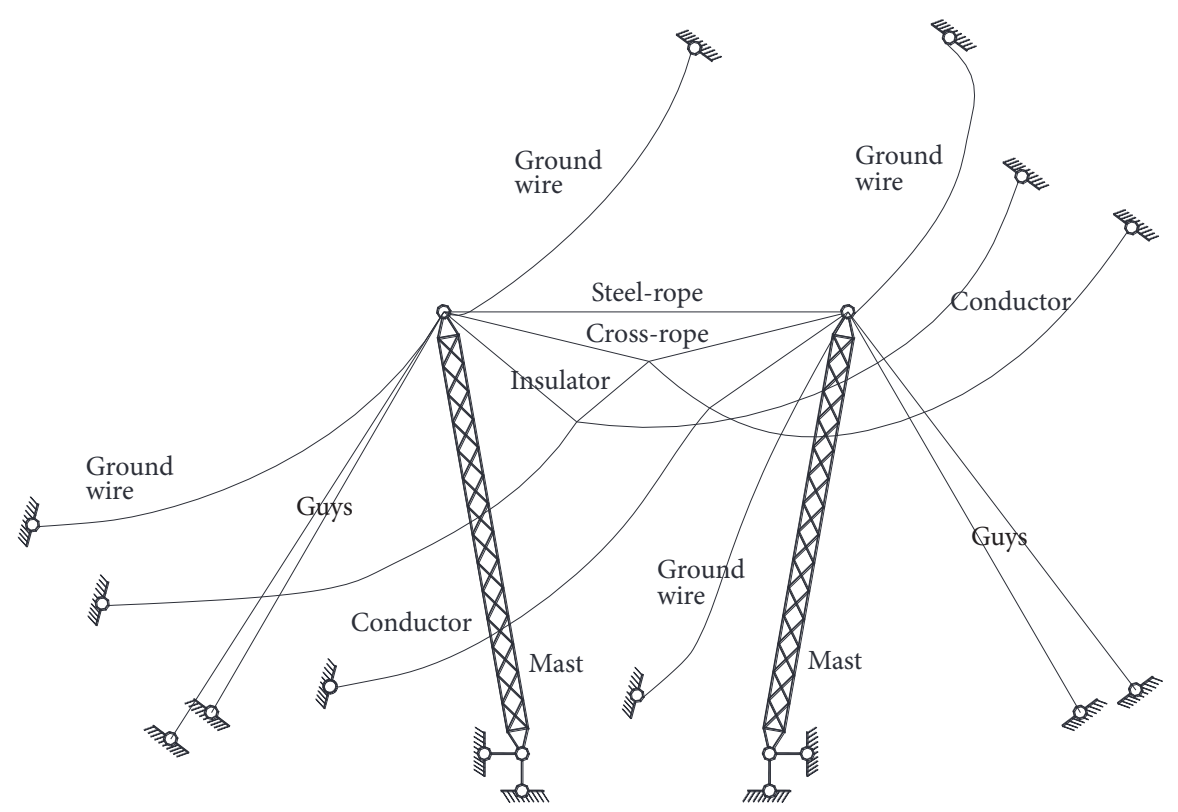

FIGURE 1: Schematic diagram of cross-rope suspension tower.

method would underestimate the dynamic response of the towers and proposed the simplified method which has been improved to more accurately estimate the dynamic effect of the towers [12]. Ballaben et al. carried out wind-induced vibration analysis of several important design parameters of guyed towers with results showing that the guy pretension was the most important variable influencing the tower top displacement of the towers [13]. Carrasco-Luzardo et al. made the analysis of the tension of guyed mast in different initial tension conditions with the results showing that the natural frequency of the mast will increase with the increase of the initial tension [14]. Wang et al. set up the nonlinear finite element model of single-mast guyed tower and studied the stress characteristic of single-mast guyed tower and the impact of the initial guy pretension on it by static analysis and made the time-history analysis of wind-induced vibration response of tower-line system $[15,16]$. And for study of crossrope suspension tower-line, at present, only the author has researched the wind-induced vibration of it under different guy pretensions and wind attack angles in wind tunnel test [17-20].

Therefore, this paper focuses on the time-history analysis of wind-induced vibration of cross-rope suspension towerline system so as to research the impact of the two important design parameters, namely, initial guy pretension and the sagspan ratio of suspension-rope, on the wind-induced vibration characteristics of it. The cross-rope suspension tower-line is shown in Figure 1.

\section{Finite Element Model of a Cross-Rope Suspension Tower-Line System}

This paper aims at setting up the finite element model of a cross-rope suspension tower, which is recommended
TABLE 1: The material list of cross-rope suspension tower-line.

\begin{tabular}{lcc}
\hline Part name & Weight $(\mathrm{kg})$ & Total $(\mathrm{kg})$ \\
\hline Masts & 28021.64 & \\
Steel-rope & 228.8 & 34202.54 \\
Cross-rope & 1726.9 & \\
Guys & 4225.2 & \\
\hline
\end{tabular}

in a UHV DC transmission line. The tower is $54 \mathrm{~m}$ high; conductors are 6-split per phase, with split spacing of $450 \mathrm{~mm}$ and horizontal span of $480 \mathrm{~m}$. The material list for cross-rope suspension tower-line is as shown in Table 1, and the specific parameter statistics are as shown in Table 2.

The main material for the double-mast is Q345 and Q235 single equal-angle steel. During the finite element modeling, BEAM188 beam element in ANSYS software was used to simulate angle steel. This type of beam element is called 3D linear finite strain beam element, suitable for the problems such as linear, large rotation, and large strain problems including stress stiffness, so as to be able to make stability analysis, the buckling analysis of characteristic value of bending, rolling motion, torsion, and so on. BEAM188 has two nodes, with 6 to 7 free degrees, 3 translational free degrees, 3 rotational free degrees, and a warping free degree in cross section for each node.

Guys, suspension-rope, and power transmission line are all catenaries. It is required to determine the initial configuration of the catenary in finite element modeling. Catenary equation is not inconvenient to use due to its complexity to a certain extent in calculation, so, catenary formula is generally simplified to parabolic formula, and, namely, approximately considering that line load is evenly distributed along suspension point connection. As shown in 
TABLE 2: The parameter of cross-rope suspension tower-line.

\begin{tabular}{lcc}
\hline Part name & Specification & Calculation of sectional area/mm $^{2}$ \\
\hline Conductor & JL/G3A-1000/45 & $1045.38(1043)$ \\
Ground wire & LBGJ-150-20AC & $162.877(148.07)$ \\
Guy & $1 \times 37-28.0-1470-B$ & 464.95 \\
Suspension-rope & $1 \times 37-28.0-1470-B$ & 464.95 \\
Insulator & & 1000 \\
Steel-rope & $1 \times 19-5.0-1470-B$ & 14.92 \\
\hline
\end{tabular}

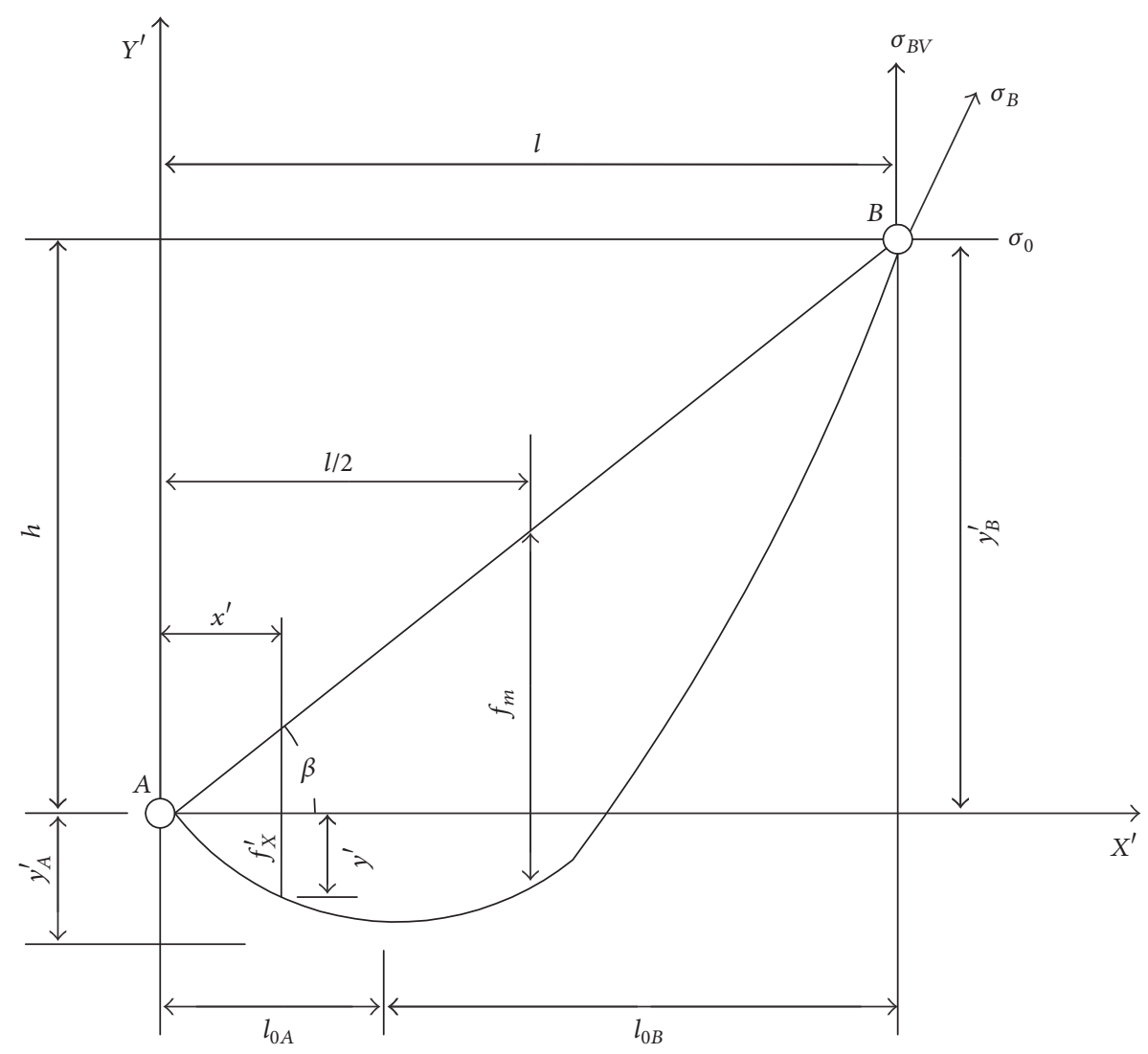

FIGURE 2: Calculation diagram of inclined parabola.

Figure 2, origin of coordinates is located at the suspension point $A$.

The curve equation of inclined parabola is shown in

$$
y^{\prime}=x^{\prime} \operatorname{tg} \beta-\frac{\gamma x^{\prime}\left(l-x^{\prime}\right)}{2 \sigma_{0} \cos \beta} .
$$

Sag formula is shown in

$$
\begin{aligned}
f_{x}^{\prime} & =\frac{\gamma x^{\prime}\left(l-x^{\prime}\right)}{2 \sigma_{0} \cos \beta}=\frac{4 x^{\prime}}{l}\left(1-\frac{x^{\prime}}{l}\right) f_{m} \\
f_{m} & =\frac{\gamma l^{2}}{8 \sigma_{0} \cos \beta} .
\end{aligned}
$$

Span is shown in

$$
L=\frac{l}{\cos \beta}+\frac{\gamma^{2} l^{3} \cos \beta}{24 \sigma_{0}^{2}} .
$$

The comprehensive value of suspension point in stress tangential direction is shown in

$$
\begin{aligned}
& \sigma_{A}=\sqrt{\sigma_{0}^{2}+\frac{\gamma^{2} l_{\mathrm{OA}}^{2}}{\cos ^{2} \beta}} \\
& \sigma_{B}=\sqrt{\sigma_{0}^{2}+\frac{\gamma^{2} l_{\mathrm{O} B}^{2}}{\cos ^{2} \beta}} .
\end{aligned}
$$




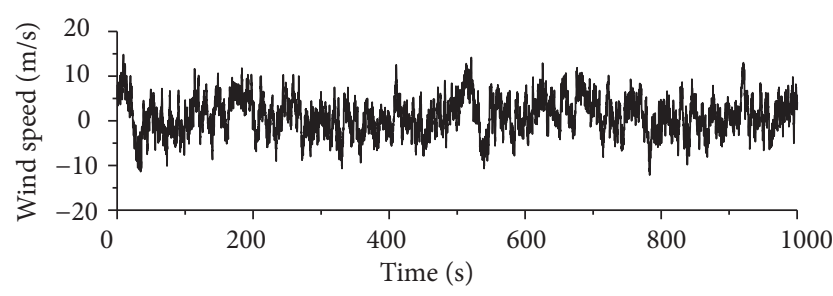

Figure 3: Time-history curve of wind speed.

Stress vertical component of the suspension point is shown in

$$
\begin{gathered}
\sigma_{A V}=\frac{\gamma}{\cos \beta} l_{\mathrm{OA}} \\
\sigma_{B V}=\frac{\gamma}{\cos \beta} l_{\mathrm{OB}} .
\end{gathered}
$$

Horizontal distance from the lowest point of parabola to suspension point is shown in

$$
\begin{aligned}
& l_{\mathrm{OA}}=\frac{l}{2}-\frac{\sigma_{0}}{\gamma} \sin \beta \\
& l_{\mathrm{OB}}=\frac{l}{2}-\frac{\sigma_{0}}{\gamma} \sin \beta .
\end{aligned}
$$

Vertical distance from the lowest point of parabola to suspension point is shown in

$$
y_{\mathrm{OA}(\mathrm{OB})}=f_{m}\left(1 \pm \frac{h}{4 f_{m}}\right)^{2} .
$$

Regarding the abovementioned equations, $l$ is span length, $h$ is height difference, $\beta$ is the angle of height difference, $f_{m}$ is the maximum sag of parabola, $\sigma_{0}$ is the horizontal stress of parabola at each point, and $\gamma$ is the relative load of parabola (i.e., the load of unit length and unit cross section). The LINK180 bar element in ANSYS software can be used to simulate catenary. This kind of bar element is called $3 \mathrm{D}$ finite strain bar element, being able to bear axial tension or compression, with the functions of plasticity, creep, rotation, large deformation, and large strain, and so on also including stress stiffening effect. LINK180 unit has two nodes, with three translational free degrees on each node.

\section{Calculation Method of Wind-Induced Vibration}

3.1. Simulation of Fluctuating Wind Field. The method of harmonic synthesis is used for numerical simulation, with 154 points of space fluctuating wind speed simulated in total. Davenport spectrum is adopted for wind speed spectrum and the index coherence function proposed by Davenport is used for frequency domain coherence function. Wind speed timehistory curve and wind speed spectrum are shown in Figures 3 and 4 .

3.2. Calculation Method of Finite Element. The Newmark method as implicit direct integral method is used to make

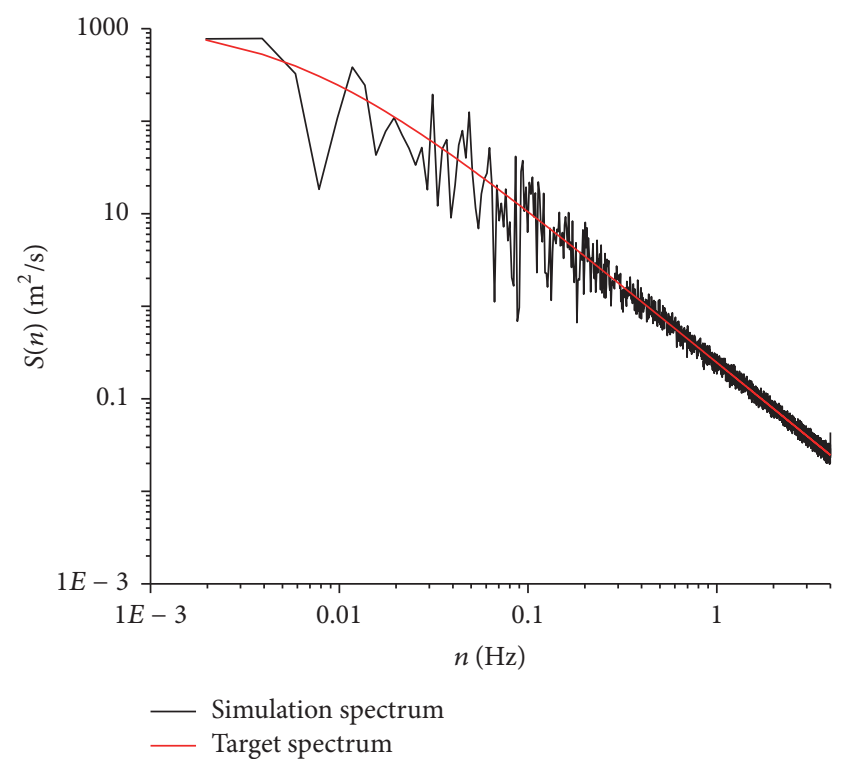

Figure 4: Wind speed spectrum.

time domain analysis of tower-line system for solution. Its solving process is briefly as follows.

The motion equation for the structure within the time of $t+\Delta t$ is shown in

$$
M X_{t+\Delta t}^{\prime \prime}+C X_{t+\Delta t}^{\prime}+K X_{t+\Delta t}=F_{t+\Delta t}
$$

Provided that it is within the time domain of $t \sim t+\Delta t$, the following two formulas should be met:

$$
\begin{aligned}
X_{t+\Delta t}^{\prime}= & X_{t}^{\prime}+\left[(1-\delta) X_{t}^{\prime \prime}+\delta X^{\prime \prime}{ }_{t+\Delta t}\right] \Delta t \\
X_{t+\Delta t}= & X_{t}+X_{t}^{\prime}{ }_{t} \Delta t \\
& +\left[\left(\frac{1}{2}-\alpha\right) X_{t}^{\prime \prime}+\alpha X_{t+\Delta t}^{\prime \prime}\right] \Delta t^{2} .
\end{aligned}
$$

It can be gotten by formula (11):

$$
\begin{aligned}
X_{t+\Delta t}^{\prime \prime}= & \frac{1}{\alpha \Delta t^{2}}\left(X_{t+\Delta t}-X_{t}\right)-\frac{1}{\alpha \Delta t} X_{t}^{\prime} \\
& -\left(\frac{1}{2 \alpha}-1\right) X^{\prime \prime}{ }_{t} .
\end{aligned}
$$

Formula (12) is substituted into (10) and then merged into formula (9); the two-step recursive formula for calculation of $X_{t+\Delta t}$, according to $X_{t} X^{\prime}{ }_{t}$ and $X^{\prime \prime}{ }_{t}$, can be gotten:

$$
\begin{aligned}
& \left(K+\frac{1}{\alpha \Delta t^{2}} M+\frac{\delta}{\alpha \Delta t} C\right) X_{t+\Delta t}=F_{t+\Delta t} \\
& +M\left[\frac{1}{\alpha \Delta t^{2}} X_{t}+\frac{1}{\alpha \Delta t} X_{t}^{\prime}+\left(\frac{1}{2 \alpha}-1\right) X^{\prime \prime}{ }_{t}\right] \\
& \quad+C\left[\frac{\delta}{\alpha \Delta t} X_{t}+\left(\frac{\delta}{\alpha}-1\right) X_{t}^{\prime}+\left(\frac{\delta}{2 \alpha}-1\right) \Delta t X^{\prime \prime}{ }_{t}\right] .
\end{aligned}
$$




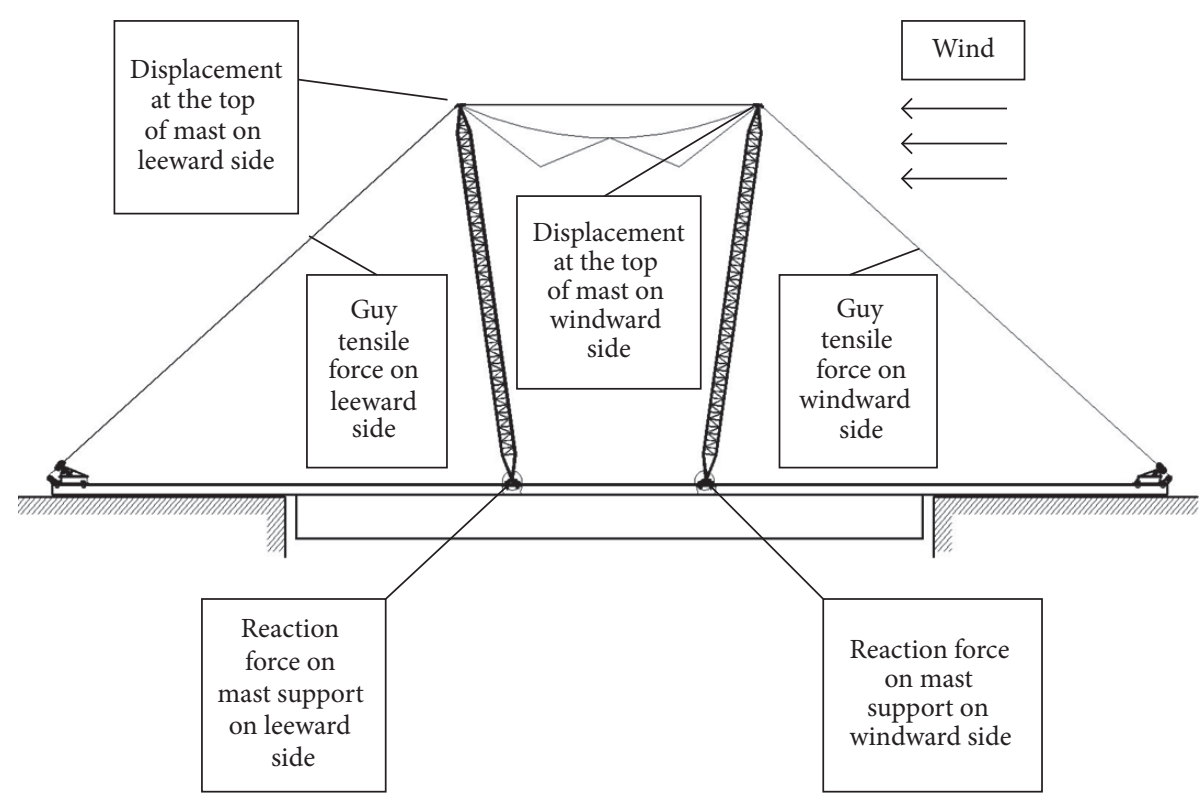

FIGURE 5: Results of response for parametric study.

\section{Parameter Analysis}

The value size of the initial guy pretension plays a key role in the overall stiffness and stability of the structure. And the suspension-rope, as the carrier bearing insulator and split conductors, is the bridge to connect the masts at both sides to realize internal force reconstruction.

In order to study the influence of these two structural design parameters, the initial guy pretensions selected in this paper are, respectively, $10 \%\left(77.94 \mathrm{~N} / \mathrm{mm}^{2}\right), 15 \%$ $\left(116.91 \mathrm{~N} / \mathrm{mm}^{2}\right), 20 \%\left(155.88 \mathrm{~N} / \mathrm{mm}^{2}\right), 25 \%\left(194.84 \mathrm{~N} / \mathrm{mm}^{2}\right)$, $30 \% \quad\left(233.81 \mathrm{~N} / \mathrm{mm}^{2}\right), \quad 35 \% \quad\left(272.78 \mathrm{~N} / \mathrm{mm}^{2}\right)$, and $40 \%$ $\left(311.75 \mathrm{~N} / \mathrm{mm}^{2}\right)$ of designed bearing capacity. Sag-span ratios of suspension-rope are chosen as 1/8, 1/9, 1/10, 1/11, and 1/12. It is required to analyze the cross-rope suspension tower-line in the $0^{\circ}$ working condition that coming wind is perpendicular to the direction of split conductors and select the guy tensile force at both sides, the reaction force on mast supports at both sides, and the displacement response at the top of masts at both sides for parametric analysis as shown in Figure 5, in which wind speed is $33 \mathrm{~m} / \mathrm{s}$ as designed.

4.1. Influence of Tensile Force on Guys. Figure 6 shows the situation of the average value and the maximum value of guy tensile force on both windward and leeward sides varying with the initial guy pretension and sag-span ratio of suspension-rope. It can be seen from the figure that, with the increase of sag-span ratio, the corresponding tensile force average value and the maximum value of guys at both sides show a trend of decrease. Under each sag-span ratio, with the increase of initial guy pretension, the average value of tensile force on guys at both sides basically increases linearly. In the case of the sag-span ratio of $1 / 8$ and $1 / 9$, the average value and maximum value of tensile force are relatively smaller than those in the case of other sag-span ratios. In the case of the sag-span ratio of $1 / 8$, the maximum value of tensile force on guys on windward side gently changes with the increase of initial guy pretension, and when the initial guy pretension is between $10 \%$ and $30 \%$, its value is relatively small. After initial guy pretension is over $30 \%$, the maximum value of tensile force on guys on leeward side increases evidently. And in the case of the sag-span ratio of $1 / 9$, the maximum value of tensile force on guys of both windward and leeward side increases evidently after initial guy pretension is over $30 \%$. When sagspan ratio is relatively small, namely, $1 / 11$ and $1 / 12$, there is an evident nonlinear effect between the maximum value of guy tensile force and the initial guy pretension on both sides. This may be because different sag-span ratios of suspension-rope have an important impact on the loaded property, internal force redistribution, and so on.

4.2. Influence of Reaction Force on Mast Support. Figure 7 shows the relational graph of the average value and the maximum value of reaction force on mast supports at both sides varying with initial guy pretension and sag-span ratio of suspension-rope, which is similar to the above-said change rule of tensile force on guys, increasing with initial guy pretension under each sag-span ratio, with the average value of reaction force on the mast supports at both sides showing a linear growth trend; when sag-span ratio is $1 / 8$, the maximum value of reaction force on mast support on windward side and leeward side is minimum. At this point, when initial guy pretension is greater than $30 \%$, the average value of reaction force on mast support on windward side will increase significantly. 


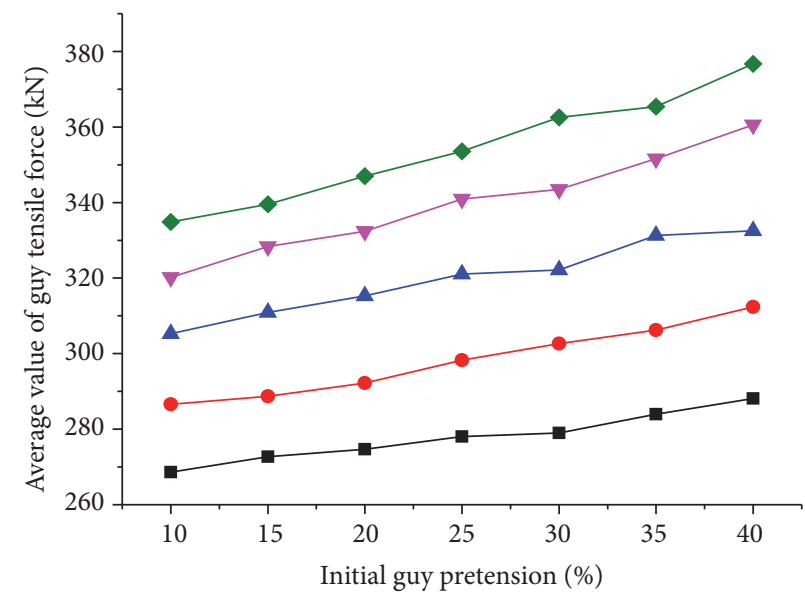

$\rightarrow$ Sag-span ratio $1 / 8 \quad \longrightarrow$ Sag-span ratio $1 / 11$
$\rightarrow$ Sag-span ratio $1 / 9$
- Sag-span ratio $1 / 10$

(a) Average value of guy tensile force on windward side

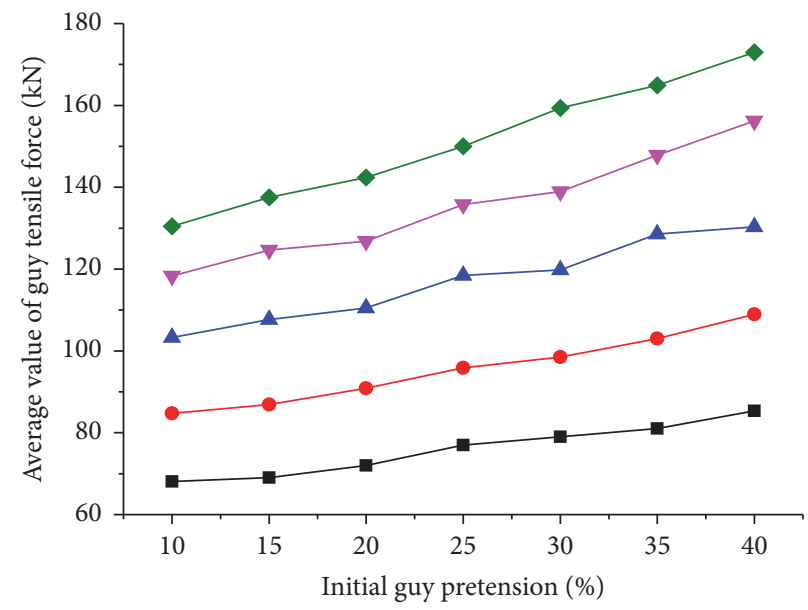

$\begin{array}{ll}\rightarrow \text { Sag-span ratio } 1 / 8 & \rightarrow \text { Sag-span ratio } 1 / 11 \\ \rightarrow \text { Sag-span ratio } 1 / 9 & - \text { Sag-span ratio } 1 / 12 \\ \rightarrow \text { Sag-span ratio } 1 / 10 & \end{array}$

(c) Average value of guy tensile force on leeward side

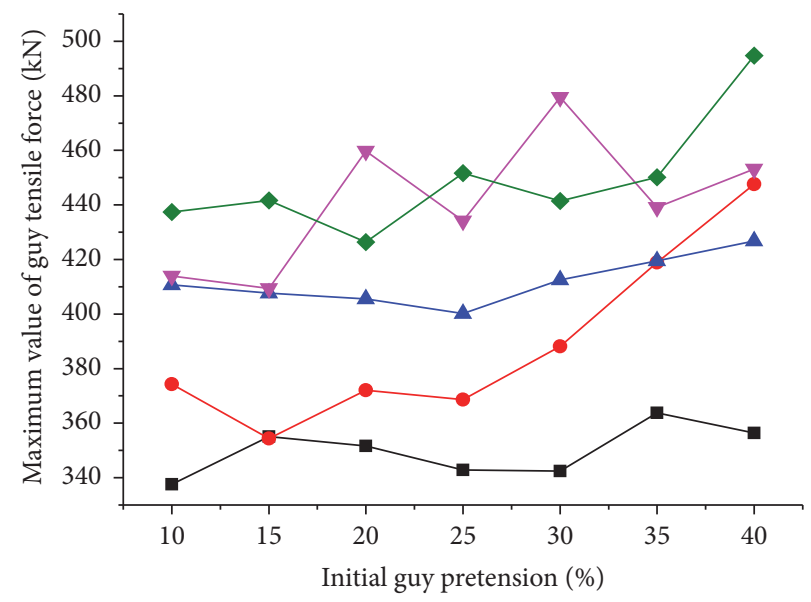

$\rightarrow$ Sag-span ratio $1 / 8 \quad \rightarrow-$ Sag-span ratio $1 / 11$

$\longrightarrow$ Sag-span ratio $1 / 9 \quad \smile$ Sag-span ratio $1 / 12$

- Sag-span ratio $1 / 10$

(b) Maximum value of guy tensile force on windward side

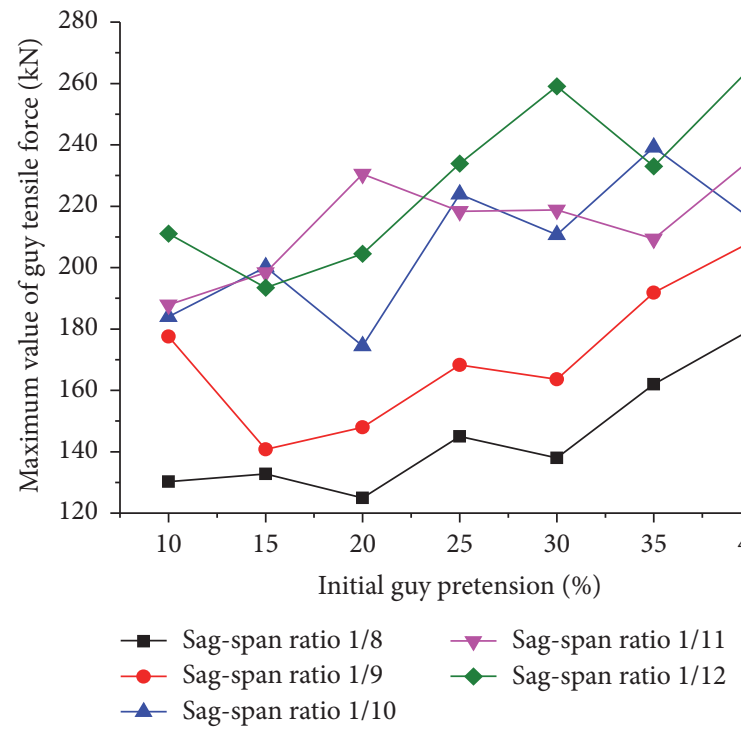

(d) Maximum value of guy tensile force on leeward side

FIGURE 6: Effect of initial guy pretension and sag-span ratio on guys.

4.3. Influence of Displacement at the Top of Masts. Figure 8 shows the change situation of the average value and the maximum value of displacement on the top of masts at both sides varying with the change of above-said two parameters. At this time, it can be seen from the figure that, with the increase of sag-span ratio, the average value and the maximum value of displacement on the top of masts on both sides are increasing. When sag-span ratio reaches $1 / 8$, the average value of displacement on the top of masts on both sides on leeward side and the maximum value of displacement on the top of mast on leeward side are larger than the others. With the increase of initial guy pretension, the average value of displacement on the top of masts on both sides decreases gradually, while the maximum value of displacement shows linear rule partially only when sag-span ratio is relatively small; in general, nonlinear effect is obvious.

\section{Further Discussion of Parameters}

From the above analysis, it is suggested that sag-span ratio of suspension-rope should be $1 / 8$ or $1 / 9$, so that the guy tensile force and the reaction force on mast supports will be kept at a small value. The displacement on the top of masts on both sides will increase, but effect is little due to very small displacement value. For the initial guy pretension, according to code for high slender structure design, for tower mast structure, it is suggested that the initial guy pretension should be selected in the range of $100 \sim 250 \mathrm{~N} / \mathrm{mm}^{2}$. It is stipulated in 

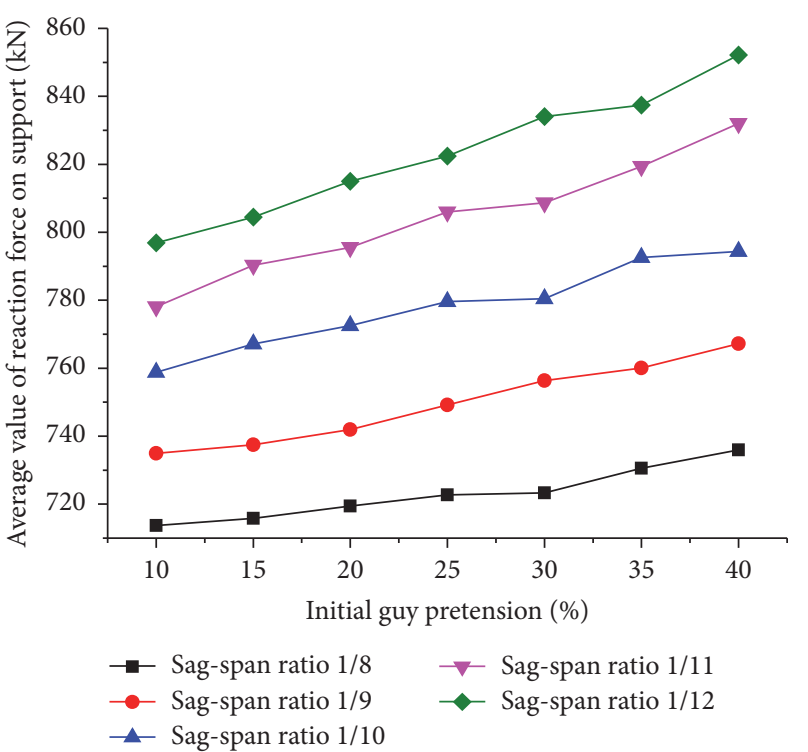

(a) Average value of reaction force on support on windward side

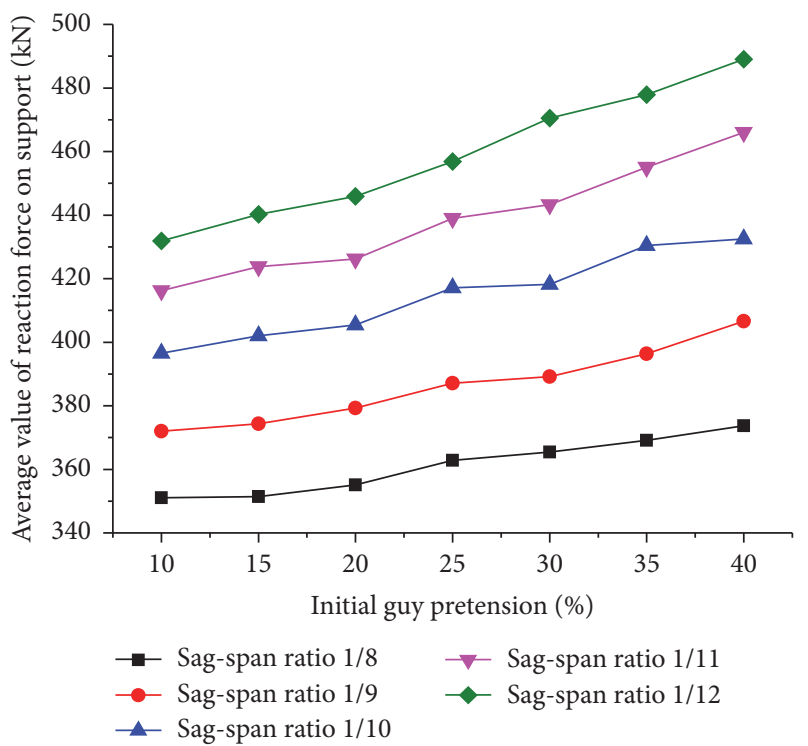

(c) Average value of reaction force on support on leeward side

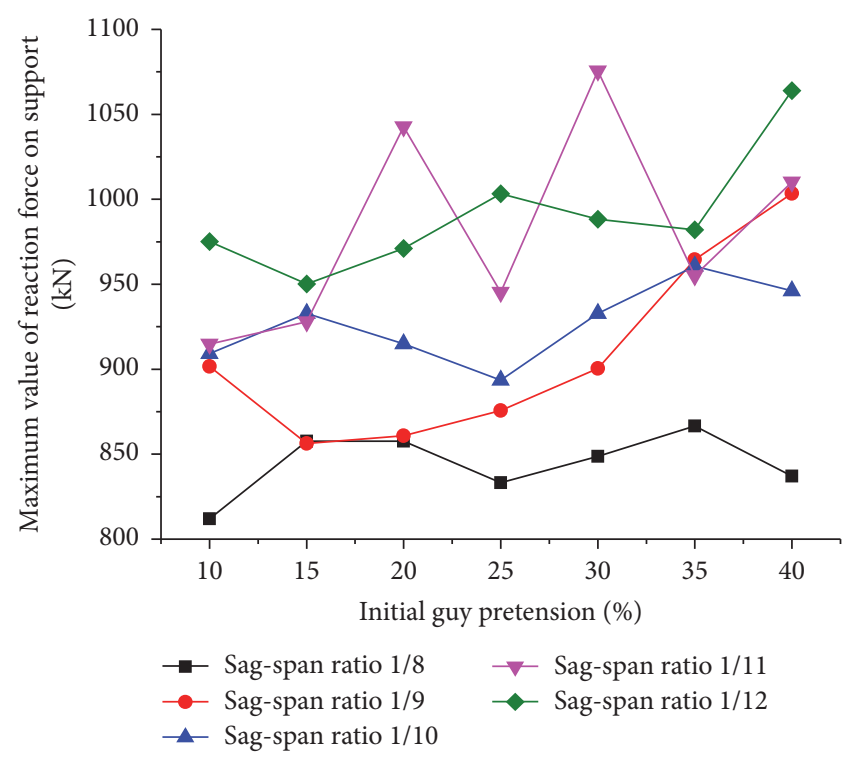

(b) Maximum value of reaction force on support on windward side

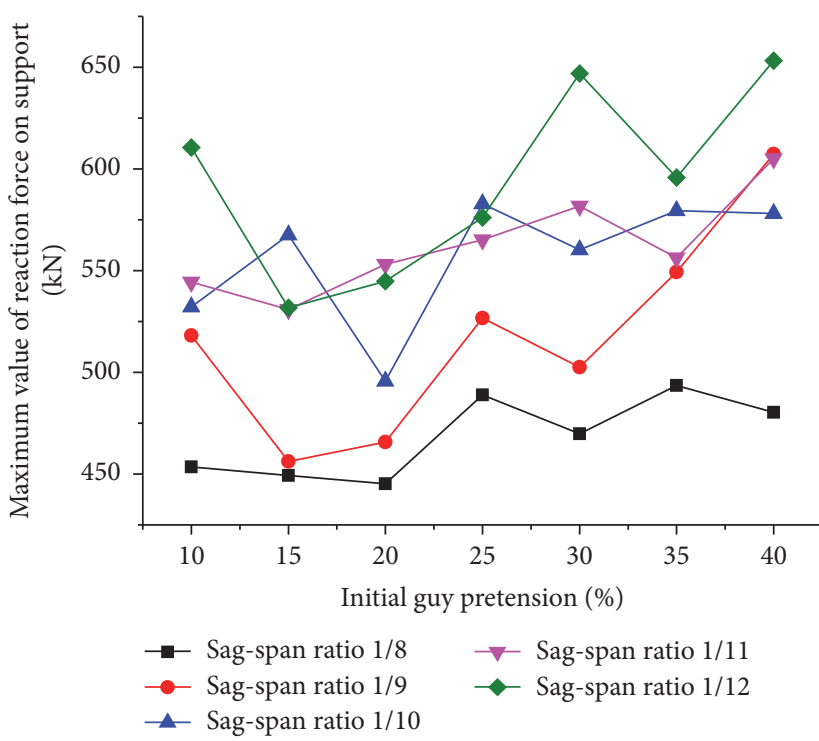

(d) Maximum value of reaction force on support on leeward side

FIGURE 7: Effect of initial guy pretension and sag-span ratio on masts.

technical regulation of design for tower and pole structures of overhead transmission line that the initial guy pretension should generally be controlled in $120 \sim 140 \mathrm{~N} / \mathrm{mm}^{2}$. According to the above analysis, for the cross-rope suspension towerline, the initial guy pretension should be controlled within $15 \%$ and $30 \%$ of designed bearing capacity.

\section{Conclusion}

In cross-rope suspension tower-line system, the initial guy pretension and the sag-span ratio of suspension-rope, as important structural design parameters, will have a significant impact on wind-induced vibration response. Therefore, this paper, from the point of view of time domain analysis, has made a variety of parameter analyses, with the main conclusions as follows:

(1) It is advisable to take $1 / 8$ or $1 / 9$ for the sag-span ratio of suspension-rope which is used to connect the masts on both sides and provide elastic support for split conductors so as to ensure making the guy tensile force kept at a smaller value at the same time when the displacement on the top of masts is smaller.

(2) Taking value for the initial guy pretension should be controlled within $15 \%$ and $30 \%$ of its designed bearing capacity. 

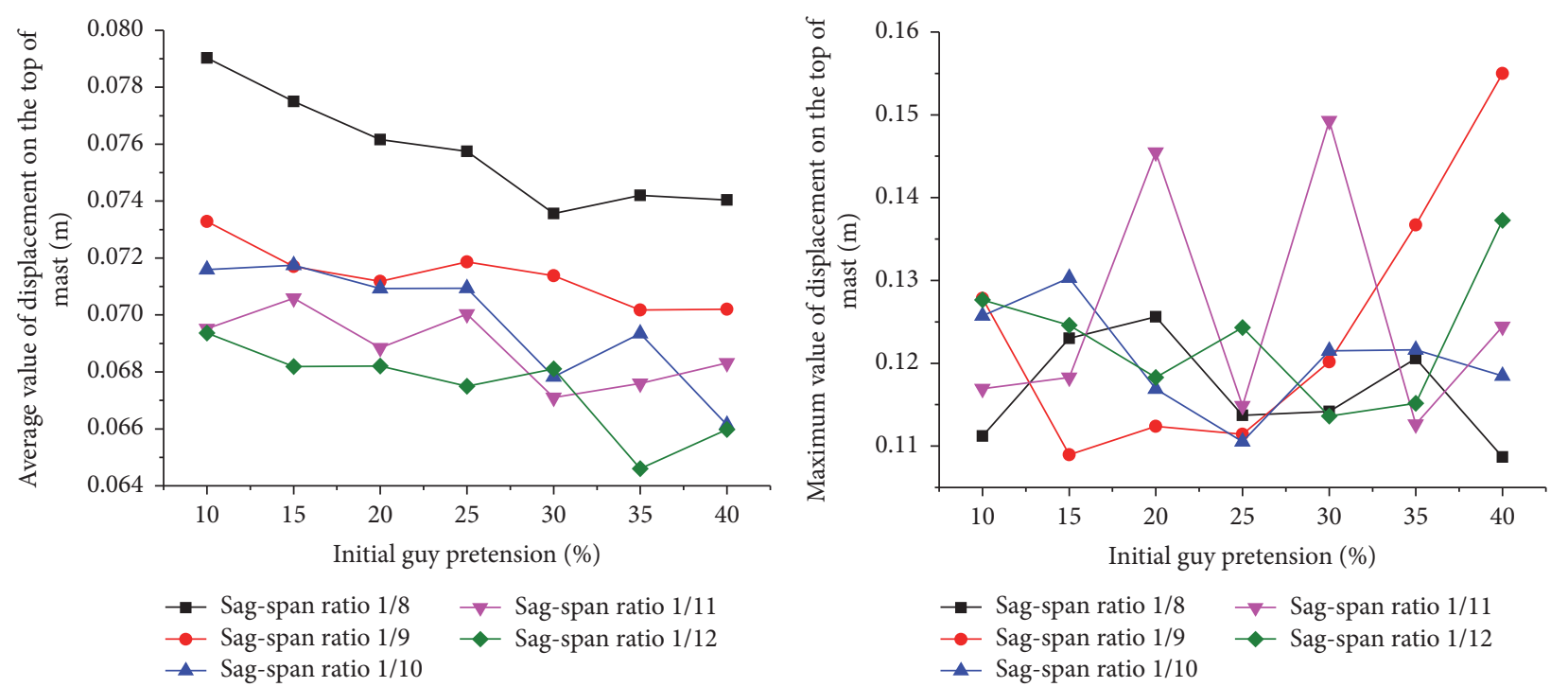

(a) Average value of displacement on the top of mast on windward side

(b) Maximum value of displacement on the top of mast on windward side
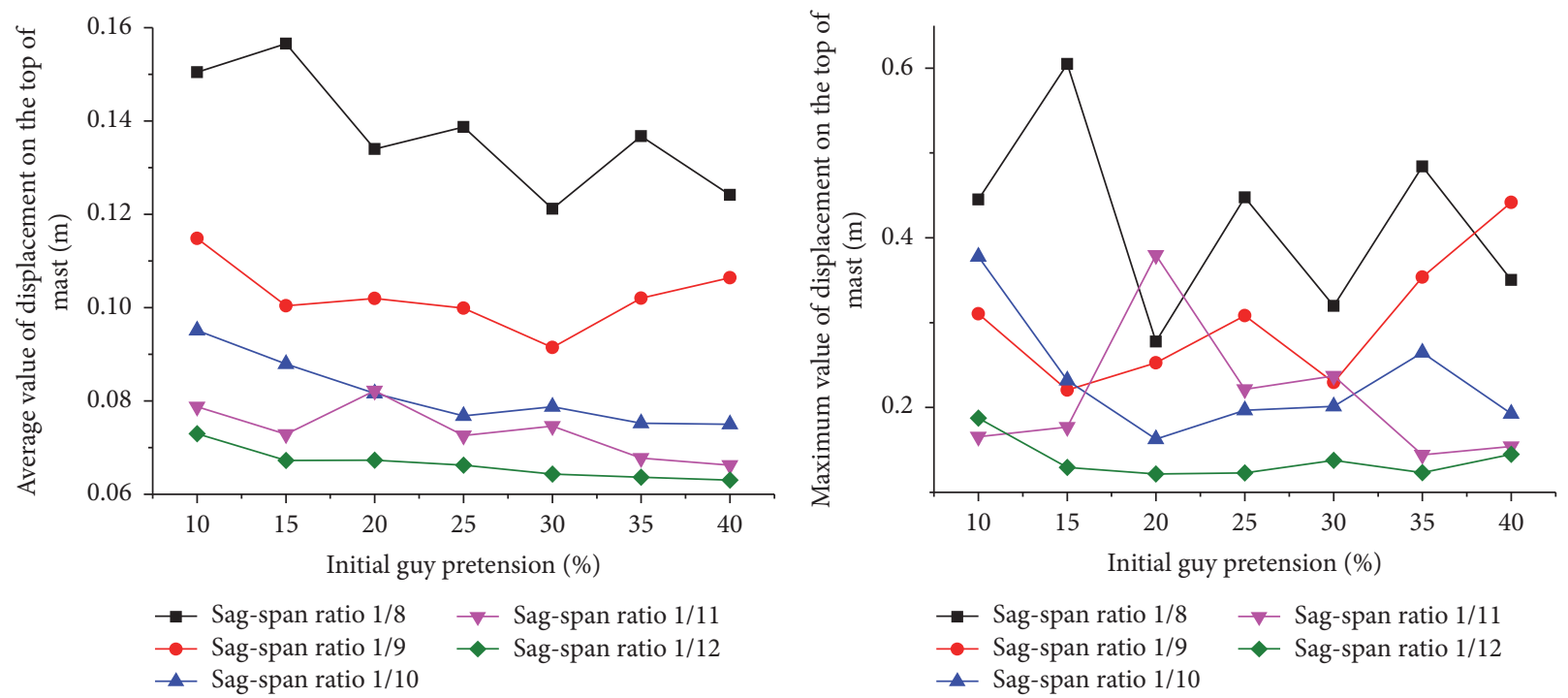

(c) Average value of displacement on the top of mast on leeward side

(d) Maximum value of displacement on the top of mast on leeward side

FIGURE 8: Effect of initial guy pretension and sag-span ratio on masts.

\section{Competing Interests}

The authors declare that there is no conflict of interests regarding the publication of this paper.

\section{References}

[1] R. R. A. Issa and R. R. Avent, "Microcomputer analysis of guyed towers as lattices," Journal of Structural Engineering, vol. 117, no. 4, pp. 1238-1256, 1991.

[2] N. Ben Kahla, "Equivalent beam-column analysis of guyed towers," Computers and Structures, vol. 55, no. 4, pp. 631-645, 1995.

[3] B. F. Sparling, The dynamic behavior of guys and guyed masts in turbulent winds [Ph.D. dissertation], University of Western Ontario, London, UK, 1995.
[4] M. K. S. Madugula, Y. M. F. Wahba, and G. R. Monforton, "Dynamic response of guyed masts," Engineering Structures, vol. 20, no. 12, pp. 1097-1101, 1998.

[5] Y. M. F. Wahba, M. K. S. Madugula, and G. R. Monforton, "Evaluation of non-linear analysis of guyed antenna towers," Computers and Structures, vol. 68, no. 1, pp. 207-212, 1998.

[6] T. H. Kewaisy, Nonlinear dynamic interaction between cables and mast of guyed-tower systems subjected to wind-induced forces [Ph.D. thesis], Texas Tech University, Lubbock, Tex, USA, 2001.

[7] Y. M. Desai and S. Punde, "Simple model for dynamic analysis of cable supported structures," Engineering Structures, vol. 23, no. 3, pp. 271-279, 2001.

[8] A. M. Horr, A. Yibulayin, and P. Disney, "Nonlinear spectral dynamic analyis of guyed towers: Part II: manitoba towers case study," Canadian Journal of Civil Engineering, vol. 31, no. 6, pp. 1061-1076, 2004. 
[9] H. Meshmesha, K. Sennah, and J. B. Kennedy, "Simple method for static and dynamic analyses of guyed towers," Structural Engineering and Mechanics, vol. 23, no. 6, pp. 635-649, 2006.

[10] H. Shi, Nonlinear finite element modeling and characterization of guyed towers under severe loading [Ph.D. thesis], University of Missouri, Columbia, Mo, USA, 2007.

[11] M. I. De Oliveira, J. G. da Silba, P. C. da Vellasco et al., "Structural analysis of guyed steel telecommunication towers for radio antennas," Journal of the Brazilian Society of Mechanical Sciences and Engineering, vol. 29, no. 2, pp. 185-195, 2007.

[12] F. Gani and F. Légeron, "Dynamic response of transmission lines guyed towers under wind loading," Canadian Journal of Civil Engineering, vol. 37, no. 3, pp. 450-464, 2010.

[13] J. Ballaben, M. Guzman, and M. Rosales, "Parametric studies of guyed towers under wind and seismic loads," The Association of Mechanical Calculation of Argentina, vol. 30, no. 1, pp. 10191032, 2011

[14] A. Carrasco-Luzardo, V. E. Parnaś, and P. Martin-Rodriguez, "Guy tension influence on the structural behavior of a guyed mast," Journal of the International Association for Shell and Spatial Structures, vol. 53, no. 172, pp. 111-116, 2012.

[15] Z. Wang, W. Yang, K. Zhang, and D. Chen, "The influence of initial guy cable prestress on UHV transmission line single mast guyed tower's mechanical properties," Proceedings of the Chinese Society of Electrical Engineering, vol. 34, no. 9, pp. 1498-1506, 2014.

[16] W. Yang, Z. Wang, B. Zhu, and L. Qi, "Time history analysis on wind-induced response of UHV guyed single-mast transmission tower-line system," Zhongguo Dianji Gongcheng Xuebao/Proceedings of the Chinese Society of Electrical Engineering, vol. 35, no. 12, pp. 3182-3191, 2015.

[17] Y. Dengke, Research on wind induced vibration of $\pm 800 \mathrm{kV} \mathrm{DC}$ cross-rope suspension tower-line [Ph.D. thesis], Department of Civil Engineering, Chongqing University, Chongqing, China, 2014.

[18] D.-K. Yu, Z.-L. Li, J.-H. Shi, Z.-T. Yan, and Z.-Z. Xiao, "Wind tunnel tests for effect of guy pretension on mechanical properties of UHV cross-rope suspension tower-line," Journal of Vibration and Shock, vol. 34, no. 13, pp. 163-168, 2015.

[19] D. Yu, Z. Li, J. Shi, Z. Yan, and Z. Xiao, "Wind tunnel test on wind-induced response of $\pm 800 \mathrm{kV}$ DC cross-rope suspension tower-line," Proceeding of the CSEE, vol. 35, no. 4, pp. 1009-1013, 2015.

[20] L. Zhengliang, Y. Dengke, X. Zhengzhi et al., "Wind tunnel test on UHV cross-rope suspension tower-line," Special Structures, vol. 31, no. 4, pp. 22-25, 2014. 


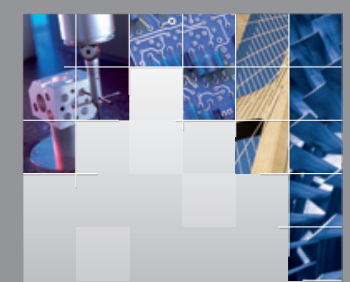

\section{Enfincering}
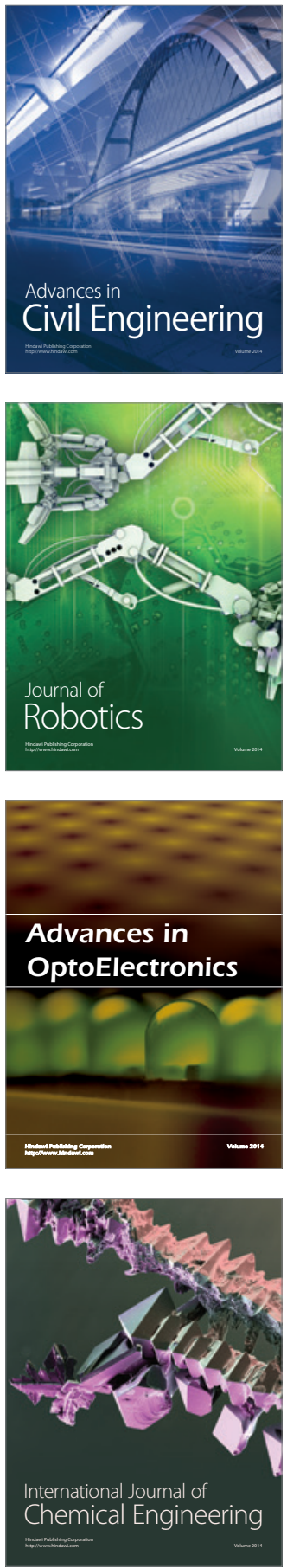

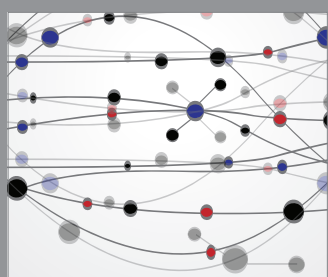

The Scientific World Journal

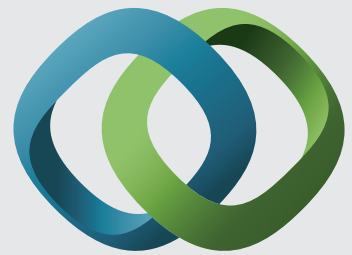

\section{Hindawi}

Submit your manuscripts at

https://www.hindawi.com
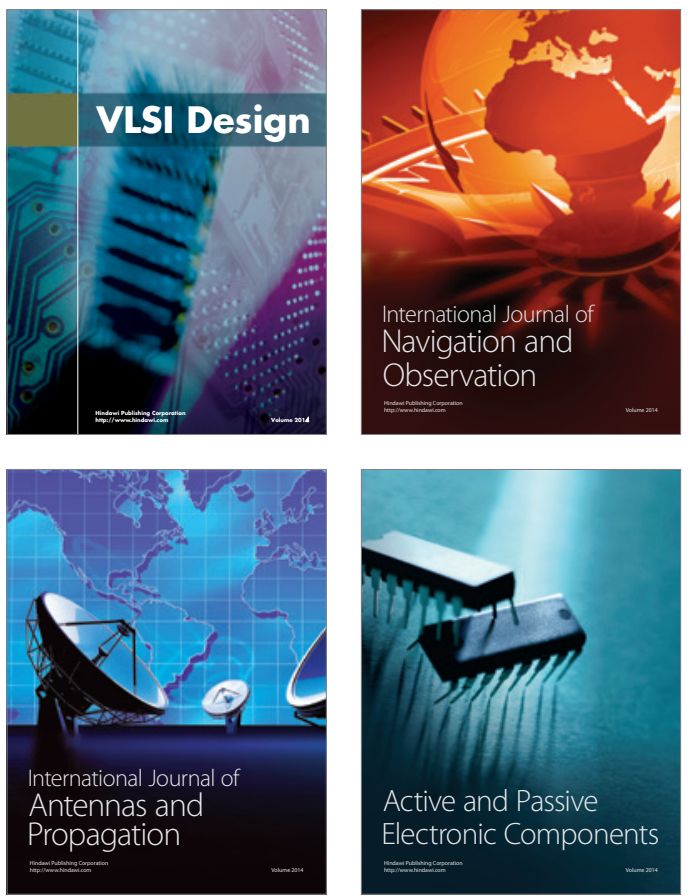
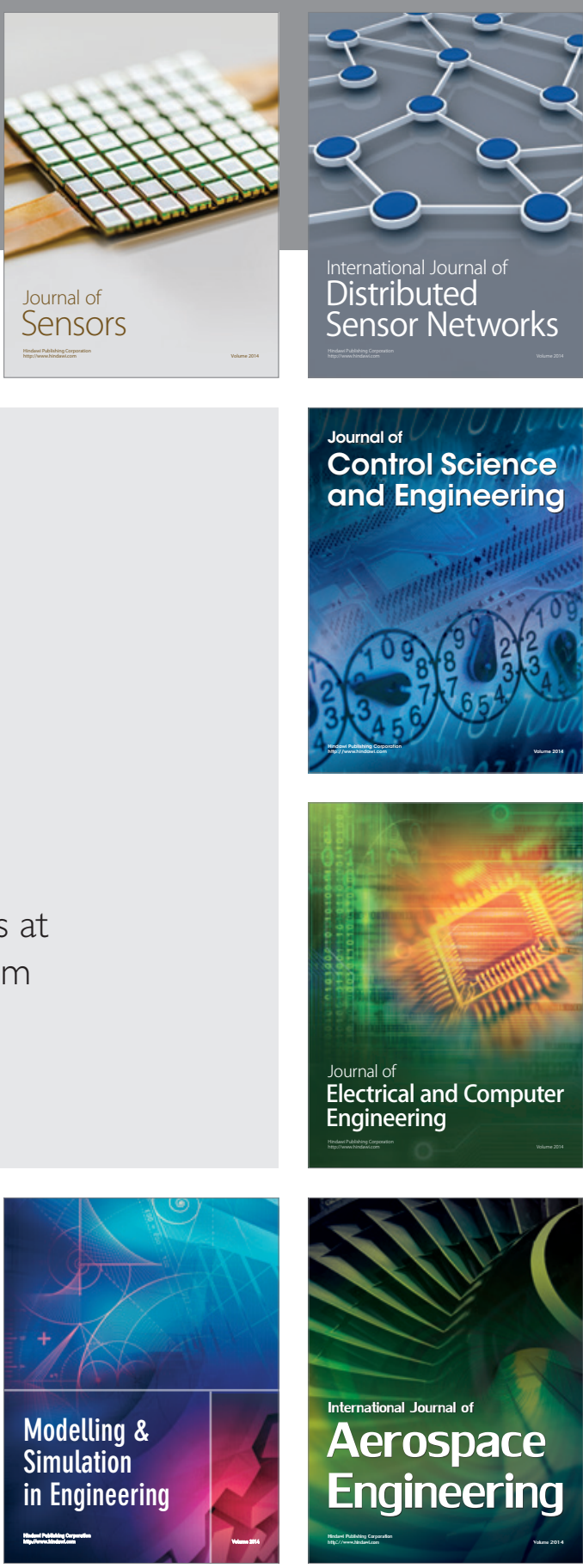

International Journal of

Distributed

Sensor Networks

$-$

Joumal of

Control Science

and Engineering
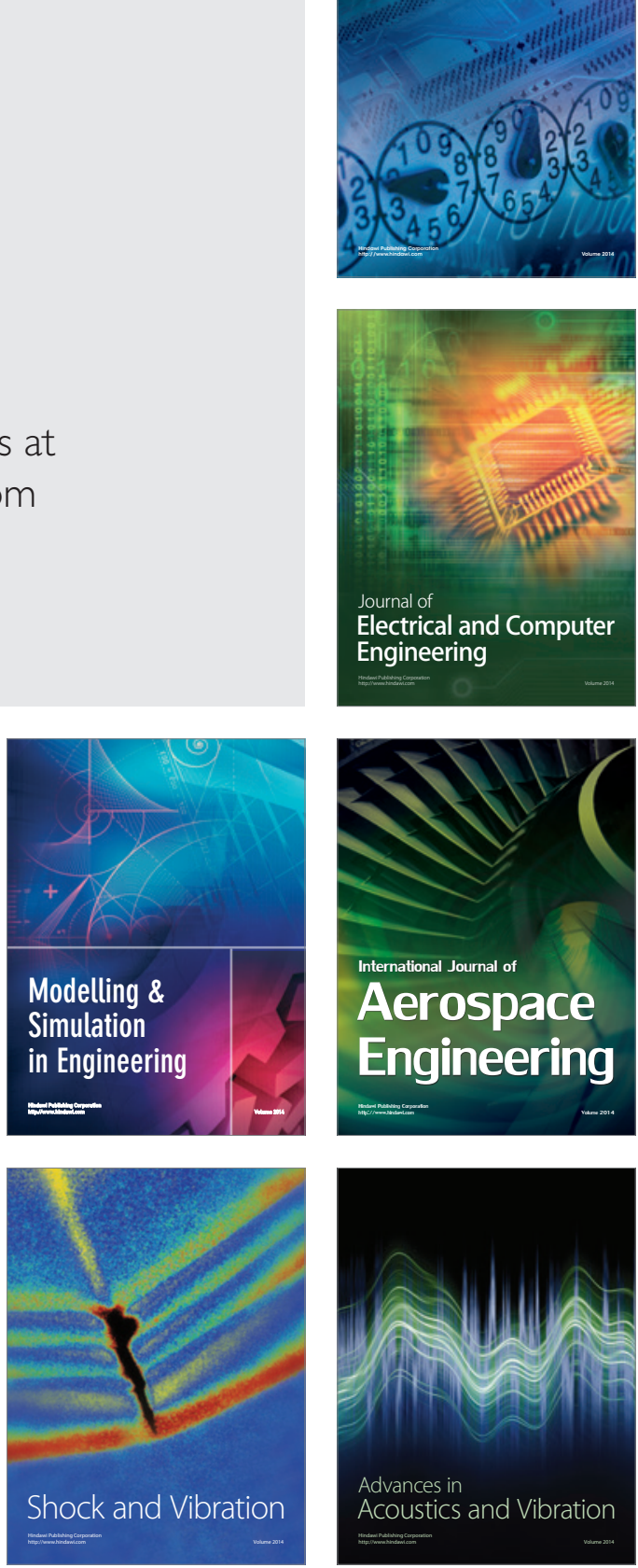